\title{
Strategic intelligence and its impact on achieving en- trepreneurship: A field study on Jordanian industrial companies that won the King Abdullah II Award for ex- cellence
}

\author{
Buthina Alobidyeen ${ }^{1 *}$, Eyad Taha Al-Rawashdeh ${ }^{2}$ \\ 1,2 Business Administration Department, Faculty of Business, Tafila Technical University, Tafilah, Jordan
}

\section{Keywords}

Strategic intelligence

Achieving Entrepreneurship

Jordanian industrial companies

King Abdullah II

Award for excellence

Received: 9 September 2019

Accepted: 13 November 2019

Published: 12 February 2020

\begin{abstract}
The study aims to identify the impact of strategic intelligence in achieving Entrepreneurship on Jordanian industrial companies that won the King Abdullah II Award for Excellence. For the achieving of the study objective, a questionnaire was developed for data collection. The study sample consisted of (200) employees chosen in a proportional stratified random method. The Statistical Package for Social Sciences (SPSS 19) was used to analyze the data. The study found the following important results: The perceptions of the study sample individuals on the level of strategic intelligence in the researched companies are of an average level, and the perceptions of the study sample individuals on the level of achieving entrepreneurship in the researched companies were of an average level. The study recommends focusing on initiating and taking the risk of seizing and expanding opportunities in markets and concluding deals between companies and alliances in a manner that helps provide distinguished services among other companies. Further, it recommends supporting entrepreneurial initiatives by the managers of the researched companies by providing a work environment that utilizes/encourages/expands energies and generates ideas that contribute to the establishment of entrepreneurial projects that lead companies to grow and continue.
\end{abstract}

(C) 2020 The Author(s). Published by TAF Publishing.

\section{INTRODUCTION}

\section{Study Background and Problem}

Organizations are beginning to realize the importance of strategic intelligence, and the need has emerged to search for new types of leaders who have distinct and unique characteristics capable of advancing organizations and reaching the highest level of advancement, entrepreneurship and excellence, especially in light of intense competition.

Similar to modern management concepts, strategic intelligence represents one of the most prominent and important of these concepts, which provides a general framework for the organization with an integrated dimensions approach. In order to be creative and achieve entrepreneurship, organizations in various fields must have strategic intelligence. Obtaining information and analyzing the work environment is extremely important at the organizational level; it requires the advantage of strategic intelligence that reflects the specific type of mental capacity that the leader needs within the organization.

Strategic intelligence is a holistic a way of thinking of the present and future of the organization, solving its problems and adapting to the internal and external environment in a way that guarantees the organization maintain its competitive position and achieve its continuous success. On the other hand, failure to apply this type of intelligence by business organizations leads to the loss of many opportunities created by the external environment and make it vulnerable to more threats that lead to its failure when facing competitors.

Hence, this research, which focuses on the impact of strate-

\footnotetext{
${ }^{*}$ corresponding author: Buthina Alobidyeen

$\dagger$ email: balobidyeen@ttu.edu.jo
} 
gic intelligence in achieving entrepreneurship in Jordanian industrial companies that won the King Abdullah II Award for Excellence, covers this important aspect of administrative leadership. This is particularly important in light of globalization, the digital economy and the technological progress that imposes on industrial companies the application of modern management curricula to continue in the market and achieve competitive advantages.

\section{Study Problem}

Jordanian companies, like companies from other developing nations, are floundering in several areas. This is due to the nature of management and the administrative approaches, , which is often to provide temporary or circumstantial solutions to address problems in a rapid manner. Because managers are interested in addressing routine and short-term issues which do not rise to the administrative level they occupy, priority is given to paying attention to issues of strategic dimensions that affect the entity of the company and threaten its future. Thus, its fate primarily depends on the accuracy and integrity of strategic decisions taken by senior management.

Therefore, the current study is concerned with addressing the issue of strategic intelligence and the extent of its contribution to achieving entrepreneurship, since Jordanian companies need to apply these modern management concepts to improve their services and steadfastness in light of global competition. Based on the foregoing, the problem of the study is presented in the following question: What is the effect of strategic intelligence practices on Jordanian companies on achieving entrepreneurship? What are the most important dimensions of strategic intelligence that are better able to explain the variance in achieving entrepreneurship for these companies?

\section{The Importance of Studying}

Theoretical and scientific aspects are the importance determined in this study.

\section{Theoretical importance is represented by the following}

1- The present study represents a purposeful attempt to contribute to knowing the relationship between strategic intelligence and achieving entrepreneurship in Jordanian industrial companies that won the King Abdullah II Award for Excellence.

2. It is considered a performance tool through which strategic intelligence can be developed and improved in the Jordanian industrial companies that won the King Abdullah II Award for Excellence. 3. It provides the ways and means by which to enhance and develop strategic intelligence.

\section{The scientific importance is represented by}

1. Its importance lies in the fact that this study is one of the rare studies that examines strategic intelligence and its impact on achieving entrepreneurship.

2. It presents the he possibility of benefiting from the results of this study and its recommendations.

\section{Study Questions}

The main question is: what is the impact of strategic intelligence on achieving entrepreneurship in Jordanian industrial companies that won the King Abdullah II Award for Excellence?

The study also seeks to answer the following sub-questions: The first question: What is the level of the respondents' perceptions about the concept of strategic intelligence in its dimensions (foresight, organized thinking, and motivation) from the viewpoint of workers in the Jordanian industrial companies that won the King Abdullah II Award for Excellence?

The second question: What is the level of the respondents' perceptions about the concept of achieving leadership in its dimensions (uniqueness, initiative, and risk), from the viewpoint of workers in the Jordanian industrial companies that won the King Abdullah II Award for Excellence?

\section{Objectives of the Study}

The research seeks to achieve the following objectives:

1. Discuss and analyze theoretical concepts related to strategic intelligence and entrepreneurship.

2. Define and describe the impact of strategic intelligence dimensions on achieving entrepreneurship.

3. Determine the level of application of strategic intelligence and entrepreneurship in Jordanian industrial companies that won the King Abdullah II Award for Excellence.

4. Provide a number of recommendations, based on the results of the study.

\section{The following sub-hypotheses follow from this hypothe- sis}

1.First sub-hypothesis: There is no statistically significant impact at the level of significance $(\alpha \leq 0.05)$ to anticipate the achievement of entrepreneurship in its dimensions (singularity, initiative, and taking risk) in Jordanian industrial companies that won the King Abdullah II Award for Excellence.

2. The second sub-hypothesis: There is no statistically significant impact at the level of significance $(\alpha \leq 0.05)$ of organized thinking in achieving entrepreneurship in its dimensions (singularity, initiation, and taking risk) in Jordanian industrial companies that have won the King Abdullah II 
Award for Excellence.

3. The third sub-hypothesis: There is no statistically significant impact at the level of significance $(\alpha \leq 0.05)$ of the strategic vision in achieving entrepreneurship in its dimensions (singularity, initiation, and taking risk) in Jordanian industrial companies that won the King Abdullah II Award for Excellence.

\section{THEORETICAL FRAMEWORK AND LITERATURE RE- VIEW}

\section{The Concept of Strategic Intelligence}

Strategic intelligence is one of the terms used to describe a specific case of intelligence within the organization. It is built on deep strategic analysis to analyze the environment and learn about its most important variables, so that the issues through which expectations for the future situation are made lead the organization to a state of stability, growth and progress (Khaddarat, 2011; Rehman, 2017).

There have been many studies that pointed to the concept of strategic intelligence through many angles. For example, (Akbari \& Safarnia, 2012; Layyinaturrobaniyah, Masyita, \& Sekartadjie, 2016) considered strategic intelligence through its effect on decision-making and rationalization of administrative decisions in the organization, since the use of dimensions and techniques of strategic intelligence facilitates the task of making strategic decisions through analysis of information accurately using smart systems, rather than confusion and randomness in collecting and analyzing information.

Gadu and El-Khameesy (2014) defined strategic intelligence as a collective term that includes various forms of intelligence to be used within an organization, including business intelligence, competitive intelligence, cognitive intelligence, and strategic intelligence.

Alternatively, (Egbuniwe, 2019; Fuld, 2016) indicated that the concept of strategic intelligence includes all the activities of the organization, and defined strategic intelligence as the essential capabilities required to make decisions which have a political impact on the future of the organization and its ability to compete with others.

Some researchers have pointed to the concept of intelligence with a holistic view in terms of the shift from traditional methods to modern methods.For example, we find that (Hawes, 2012) defined the concept of strategic intelligence as a general activity that moves the organization from a traditional situation based on trial and error to a new situation based on the use of different intelligence methods to deal with environmental variables. He suggested a hierarchical model based on smart experience created through a supply of skills and ideas that the organization work to develop in line with the requirements of the transition to strategic intelligence.

Jandab (2017) defined organizational intelligence as the organization's intellectual ability to enable it to understand problems and solve them through the information available to them, and it includes all the talents and mental capabilities to achieve its tasks and goals.

\section{The Importance of Strategic Intelligence}

Strategic intelligence plays a vital role in the development of the strategy, especially in light of the changing work environment and the accompanying challenges that requires decision makers to use all intelligence techniques to meet these challenges (Al-Qasim, 2013).

Likewise, strategic intelligence contributes to the enhancement of organizational intelligence and the resulting innovations that contribute to the improvement of the organization's products and its development, by carefully anticipating and monitoring environmental changes and taking advantage of the opportunities available to them imposed by environmental changes (Herring, 1992).

(Goleman, 2001) identified the importance of strategic intelligence as follows:

1- Contributing to changing the required works efficiently. 2- Helping the organization to adapt to the environment , changes and pressures it imposes.

3- Identifying the field of competition within the framework of the organization.

4- Assisting management in the process of rationalizing decision-making by providing appropriate information to the decision-maker.

\section{Dimensions of Strategic Intelligence}

The researchers identified a set of dimensions of the strategic intelligence that would be the focus of the current study as follows (Hijazi, 2011).

\section{Foresight (Insight, perception, prediction)}

The word foresight came in the book of Allah, the Noble Qur'an in (Al-Hashr: verse 18) "O, you who have believed, fear Allāh. And let every soul look to what it has put forth for tomorrow - and fear Allāh. Indeed, Allāh is Aware of what you do". This verse expresses the leader's ability to think in the form of invisible forces, but it creates the future and shows the importance of the element in employing intelligence to leaders of organizations in the following areas:

1- Adopting the expectation to manage environmental changes in a calm and orderly manner.

2- The success of the leaders in adopting the scenarios by 
providing a description of future alternative events and sensing environmental changes in a strong, invisible form. 3- Providing inductive energy that allows the leader to develop strategies directed towards achieving the strategic goals of the organization.

4- Leaders understanding of the main organizational processes, enhance their choices and advance their knowledge and practical experience (Asrizam et al., 2018; Gadu \& ElKhameesy, 2014).

\section{Organized thinking}

It expresses the ability to synthesize and integrate elements, rather than separating them into parts, then analyzing them together and evaluating them in terms of their relationship to the whole, and focusing on the way they interact with each other in terms of their success in serving the goals of the system (McGonagle \& Vella, 1996).

\section{Strategic vision}

The formation and formulation of the strategic vision depends not only on having mental training aimed at drafting an attractive logo for the company, but rather it is training on careful thinking in the direction that the company must go in order to achieve success, and this includes identifying the areas of the market in which it participates, and setting the company is on the right strategic path, and the commitment to follow this path leading to achieving the goals (Gadu \& El-Khameesy, 2014).

\section{The Concept of Entrepreneurship}

Many organizations are looking for good practices to survive in the competitive environment for business, and entrepreneurship is one of the means that helps organizations to enhance the competitive position. The basic idea in the field of entrepreneurship is to invest opportunities and search for value, and it is natural to point out that entrepreneurship as a phenomenon is found throughout civilization.I It has been defined as the whole of characteristics and behaviors associated with the creative and innovative capabilities (Al-Qasim, 2013).

Some researchers defined it as "all the creative procedures that the individual offers within the organization in order to find a new entrepreneurial project with the aim of providing something distinctive that fulfills the desires of customers and achieves added value that can be added to the service or the procedures (Hijazi, 2011).

The concept of entrepreneurship a lot of organizations are looking for is the practices to survive in the competitive environment for business. Leadership is one of the means that helps organizations to enhance the competitive posi- tion. Humanity has been defined as the totality of characteristics and behaviors associated with creative and innovative capabilities (Al-Qasim, 2013).

\section{Entrepreneurship strategies}

These are strategies that encourage organizations to promote creativity, innovation, singularity, risk-taking and initiation, as well as encourage workers to make decisions and take responsibility (Goleman, 2001).

The entrepreneurial strategy consists of the following policies: (uniqueness, initiative, and taking risk) and are the same dimensions that the study adopted.

1-Singularity: It is the introduction of new methods, whether technological, or new ways of providing service, or in the management and structure of the organization in a different way from others. Singularity is formed in business organizations through its ability to be distinguished from other competing organizations in the same business sector, whether by the nature of services, or by the nature of the resources it possesses, which enables them to achieve competitive advantage and achieve continuity. In the long run, the advantage can only be achieved through exceptional or distinguished resources (McGonagle \& Vella, 1996).

Singularity of the organizations was defined as: the uniquenss of the organization. This strategy relates to the possibility of achieving a competitive advantage for the organization by providing new services that makes the beneficiary feel that they are unique and distinct. This distinction can be achieved in the following areas: the technology used, excellence in the form of service or its features, and the quality of the organization's performance of this service, as well as its distinct human resources with cultural skills, capabilities and competencies that enable it to perform its business efficiently and respond to customer needs (Al-Sakarneh, 2010).

2- Initiation: It is participation in future problems, needs and changes, and the extent of providing services, technology and administrative techniques. It is also taking a higher risk than the surrounding organizations, and it includes three main elements: (Al-Sakarneh, 2008).

1- Acknowledgment of pursuing or not pursuing competitors with creativity.

2- Comparison between the real attempts at growth, creativity and development.

3- Attempts to cooperate with competitors in order to control them.

3-Taking risk: It is is to take the risk of introducing new products to the market, taking into account the ambiguity and uncertainty in the market, but also seeking opportuni- 
ties that the organization must take advantage of in order to increase its competitiveness (Al-Sakarneh, 2010).

The risk represents the willingness of the management to invest its resources in order to invest in opportunities in conditions of uncertainty. Taking risk is the organization's attempt to introduce new products whose degree of uncertainty of success in the market is high, or entering into new markets characterized by a high rate of risk where risk is linked closely with the initiative of managers in their pursuit to hunt a new opportunities in the business environment that involve risks and inclination for entrepreneurial creativity (Al-Sakarneh, 2008).

While UNESCO sees risk as an expression of the probability of an event and uncertainty about its occurrence, in case it happens, the event of its occurring may have a positive impact through the opportunities it presents to the organization, or a negative impact through the threats that will face the achievement of the goals of the organization (Hijazi, 2011).

Risk categories: Risks are divided into a group of categories, including internal and external risks that affect the organization's activities and operations. Some of these risks may be unexpected and are linked to structural reasons, not to specific activities.

\section{Previous Studies}

Al-Qadi (2019), entitled: "The Impact of Strategic Intelligence on Organizational Innovation, Knowledge Management is an Intermediate Variable, An Applied Study on Executives in Commercial Banks Operating in the Hashemite Kingdom of Jordan". The study community is the commercial banks operating in the Hashemite Kingdom of Jordan. The study sample included (13) Jordanian commercial banks, (6) banks were selected.

Bakr (2018) study entitled: "The impact of strategic intelligence on organizational creativity, an applied study on the University of Najran, the study aimed at knowing the role of strategic intelligence in developing organizational creativity." An analytical descriptive approach was used to achieve the objectives of the study. To achieve the aims of the study, the descriptive analytical method was used, the study tool was the questionnaire developed by the researcher to collect data. The study sample consisted of (91) faculty members, who were chosen using a simple random sample method. To reach the results of the study, descriptive statistical methods were used, the study found that all dimensions of strategic intelligence (foresight, organized thinking, motivation, partnership, and strategic vision) have a statistically significant impact on organizational creativity, and that the level of application of strategic intelligence in all its dimensions came with a high degree. The study recommended: The necessity of working to enhance and activate the role of faculty members, their participation in all activities within the university, and the exploitation of their scientific capabilities to serve the interest of the university. The study found many results, most notably i) the presence of a statistically significant impact of strategic intelligence on achieving organizational creativity in Jordanian commercial banks; ii) the presence of a statistically significant impact of strategic intelligence on knowledge management in Jordanian commercial banks; and iii)the presence of a statistically significant impact of strategic intelligence on organizational creativity through knowledge management and an intermediate variable in Jordanian commercial banks. The study recommended the necessity of investing in strategic intelligence operations by Jordanian commercial banks in order to benefit from its repercussions in achieving organizational creativity.

Lemon (2018) study, entitled: "Practices of managing the diversity of human resources and their impact on achieving entrepreneurship in universities: a field study - Jordanian public universities." To achieve the objectives of the study, a questionnaire was developed for the purpose of collecting data, the study community consisted of faculty members from all the following academic ranks: professor, associate professor, assistant professor, lecturer, and teacher at the Jordanian public universities, who number is (7433). The questionnaire was distributed to a sample that was chosen in a proportional, stratified random manner, amounting to (400) individuals, and representing (5\%) of the study population. The number of questionnaires used for the analysis was (350), and the study data was used in descriptive statistics and inferential statistics. The study reached the following important results: The respondents' perceptions of the dimensions of human resource diversity management practices in their dimensions have come at a moderate degree. The study recommends the necessity of activating the role of the university to benefit from the advantages of positive human resources diversity effectively as an administrative method in performing tasks through training programs that develop entrepreneurial skills, and working to institutionalize these programs.

Al-Dulaimi (2018) study, entitled: "The Impact of Transformational Leadership Practices on Achieving Entrepreneurship: A Field Study in Private Colleges in Iraq", the study population consisted of all Iraqi private colleges in Baghdad Governorate, and the researcher relied on the intentional sample method to survey the study community. The sample 
reached 177 respondents, and the questionnaire was used as a means to obtain data. A number of statistical methods were used, including: arithmetic mean, and the multiple linear regression test. The study found several results, most notably: The mathematical means of the transformational leadership variables as a whole have come at a high level. $\mathrm{Tt}$ has been found that there is a positive impact of statistical significance for transformational leadership practices with their dimensions in achieving entrepreneurship in private colleges in Iraq. The study concluded with a number of recommendations, including: That college leaders open horizons for employees and their participation in decisionmaking and work to provide courses that are concerned with spreading the culture of entrepreneurship within college programs.

A study of Abdel (2017), entitled: "Strategic intelligence of senior management and its reflection in enhancing the cohesion of the group." The study was aimed at determining the nature of the relationship between strategic intelligence for senior management and its impact on enhancing the cohesion of the group in the General Company for Iraqi Railways. A simple random sample consisting of (29) individuals in the company was selected, and a questionnaire was used as a tool to obtain the study data, which was prepared on a number of ready-made measures after being subjected to tests of validity and reliability. The study reached a number of results, the most important of which are: a correlation relationship and a statistically significant impact of strategic intelligence in group cohesion. The study also found that the level of application of strategic intelligence in the researched company came with a high degree. The study recommended that the researched company determine the most important areas that enjoy the field of strategic intelligence, which can be use to enhance group cohesion.

A study of Jandab (2017), entitled: "The impact of information technology on entrepreneurial strategies in Yemeni telecom companies." The researcher used the descriptive analytical approach to deal with data as it describes the phenomenon and the researched community, and a te questionnaire was used to collect data related to the study variables. It was analyzed by the Statistical Package for SPSS. The study sample consisted of (288) individuals from managers and heads of departments in all telecom companies, namely: (Yemen Mobile, MTN, Sabafon and Y Telecom), (274) questionnaires were valid for analysis. The study reached a set of results, the most prominent of which was the presence of a statistically significant impact of information technology in its dimensions on entrepreneurial strategies in its dimensions in Yemeni telecom companies. Among the most prominent recommendations was the need to strengthen and develop communication networks,. It further recommended the acquisition of modern equipment and external software to enhance the performance of networks in these companies as they have obvious implications for achieving entrepreneurial strategies.

Lemon (2018) study entitled: "Using Strategic Intelligence to Sustain Innovation" It is a theoretical study that focused on distinguishing between supply and demand strategies for strategic intelligence, the study concluded that the adoption of the policy of strategic intelligence in business organizations directly affects creativity, and that the support of senior management to apply strategic intelligence contributes effectively to creating an innovative environment. The study recommended the necessity of adopting the concept of strategic intelligence in organizations with all of its dimensions for its important and effective role in achieving creativity in the organization. eEncouraging creativity contributes positively to the organization's excellence and achieving more competitive advantages.

McGonagle and Vella (1996) study entitled, "The Role of Strategic Intelligence in Innovation". The research adopted the descriptive analytical approach, and used the questionnaire as a tool to collect the necessary data from the study community, which represents all managers working in a number of the American insurance companies. The study community included (65) companies, and a regular random sample of (800) individuals were taken from the study population. The study reached a number of results: Strategic intelligence has an impact on creativity in these American insurance companies. The study recommended the necessity of paying attention to applying all dimensions of strategic intelligence in the researched companies because of its important role in achieving and supporting organizational creativity.

\section{RESEARCH METHODOLOGY}

\section{Method of the study}

The descriptive analytical approach applied on this study.

\section{Population of the study}

The study population consisted of all individuals working at the rank of (director, assistant director, and head of department) in Jordanian industrial companies that won the King Abdullah II Award for Excellence more than once. There were (3) companies, and about (450) department managers, assistant directors, and heads of department. 


\section{The study sample}

The study sample was chosen in a random, stratified, proportional manner with (200) employees with the rank from the three companies, as shown in Table 1.The following ta- ble shows the distribution of the study sample individuals according to their personal and functional variables.

TABLE 1. The names of the two award-winning companies

\begin{tabular}{lll}
\hline \hline No. & Company Name & Year of Winning the Award \\
\hline 1 & Jordanian Ice, Soda, and Gasoz Company (Pepsi) & $2008 / 20092010 / 2011$ \\
2 & Fine company for manufacturing of sanitary paper & $2012 / 20132014 / 2015$ \\
3 & Petra Aluminum Company & $2010 / 20112012 / 2013$ \\
\hline \hline
\end{tabular}

TABLE 2. Distribution of study sample individuals according to their personal and functional

\begin{tabular}{|c|c|c|c|}
\hline Variable & No & Variable Categories & Percentages \\
\hline \multirow[t]{3}{*}{ Sex } & 140 & Males & 81.4 \\
\hline & 32 & Females & 18.6 \\
\hline & 172 & Total & 100.0 \\
\hline \multirow[t]{5}{*}{ Age } & 44 & Less than 30 & 25.5 \\
\hline & 62 & $30-40$ yrs & 36.1 \\
\hline & 56 & 40-less than 50 & 32.6 \\
\hline & 10 & More than 50 & 5.8 \\
\hline & 172 & Total & 100.0 \\
\hline \multirow[t]{5}{*}{ Qualifications } & 19 & $\begin{array}{l}\text { Community college } \\
\text { diploma }\end{array}$ & 11.1 \\
\hline & 124 & Bachelor & 72.1 \\
\hline & 22 & Master & 12.7 \\
\hline & 7 & Ph.D & 4.1 \\
\hline & 172 & Total & 100 \\
\hline \multirow[t]{4}{*}{ Career Level } & 40 & Director & 23.4 \\
\hline & 65 & Head of Dept & 37.7 \\
\hline & 67 & Assistant Director & 38.9 \\
\hline & 172 & Total & 100 \\
\hline \multirow[t]{4}{*}{ Experience } & 32 & Less Than 5 years & 18.6 \\
\hline & 65 & $5-10$ years & 37.7 \\
\hline & 53 & $10-15$ years & 30.9 \\
\hline & 22 & More than 15 years & 12.8 \\
\hline Variable & 172 & Total & 100.0 \\
\hline
\end{tabular}

\section{Study Tool, Data and Information Collection Methods}

A questionnaire was developed based on Likert's fivechoice scale, which ranges between totally agree and never agree, with a relative weight (5-1), and the questionnaire was divided into two main groups: the first is concerned with the personal and functional data of the respondents, and the second is at the core of the research subject. It includes number of questions that relate to three main axies of the independent variable (strategic intelligence), which are: foresight, organized thinking, and strategic vision. The dependent variable (achieving entrepreneurship) which includes are: singularity, initiation, and taking risk also covered with number of questions.

\section{Validity}

The internal consistency coefficient of the study instrument was extracted, based on the Cronbach's Alpha scale for each of the study variables in all its dimensions, and the stability coefficient values were high, indicating the stability and consistency between the tool's paragraphs, and the following Table 3 shows the validity coefficient values.

It is noted from Table 3 that the validity coefficients for all study variables are high and suitable for the purposes of the study. It is observed through the high validity rate that there is a great homogeneity among the respondents in order to the answer of the study questions and hypotheses validity test. 
TABLE 3. Distribution of study sample individuals according to their personal and functional variables

\begin{tabular}{llll}
\hline \hline Variable & Dimension & Items & Cronbach \\
\hline 0.792 & $1-3$ & Foresight & \\
0.740 & $4-7$ & Organized thinking & Independent variable \\
0.845 & $8-11$ & Strategic vision & Strategic intelligence \\
0.820 & $12-15$ & Singularity & Dependent variable \\
0.890 & $16-19$ & Initiation & Achieving \\
0.786 & $20-23$ & Taking risk & Entrepreneurship \\
\hline \hline
\end{tabular}

\section{Statistical Processing}

The study relied on spss.19 in the statistical analysis through the use of statistical methods in order to describe the characteristics of the sample depending on the frequencies and percentages to answer the study questions and was based on the arithmetic means and the standard deviations, the correlation coefficient, the regression analysis matrix and the mono-variance analysis (ANOVA).

\section{RESULTS}

The presentation of the results of the descriptive statistics of the data comes as the value of the arithmetic mean, the standard deviations of the study dimensions and the component parts for each dimension.

\section{Answering the Study Questions}

Answer to the first question: What is the level of respondents' perceptions about the concept of strategic intelligence in its dimensions (foresight, organized thinking, and strategic vision) from the viewpoint of workers in Jordanian industrial companies that won the King Abdullah II Award for Excellence?

TABLE 4. Arithmetic means and standard deviations for the level of strategic intelligence with its dimensions in descending order according to the arithmetic mean

\begin{tabular}{llllll}
\hline \hline Item & Variable & Mean & Standard Deviation & Variable & Level According to Mean \\
\hline $1-3$ & Foresight & 3.76 & 0.72 & Foresight & High \\
$4-7$ & Organized thinking & 3.45 & 0.79 & Organized thinking & medium \\
$8-11$ & Strategic vision & 3.59 & 1.05 & Strategic vision & high \\
$11-1$ & Total mean & 3.60 & 0.70 & Total mean & Medium \\
\hline \hline
\end{tabular}

The statistical data in Table 4 indicate that the dimensions of the independent variable (Strategic Intelligence) came as an intermediate with an arithmetic mean (3.60) The foresight dimension ranked first with an arithmetic mean (3.76) followed by a strategic vision with an arithmetic mean (3.59), and last came the organized thinking dimension with a mean of 3.45).The results indicate that the dimensions of the strategic intelligence variable were avail- able in the high and medium-sized companies.

Answer to the second question: What is the level of respondents' perceptions about the concept of achieving entrepreneurship in its dimensions (singularity, initiation, and taking risk), from the viewpoint of workers in Jordanian industrial companies that won the King Abdullah II Award for Excellence.

TABLE 5. Arithmetic means and standard deviations to achieve entrepreneurship in its dimensions

\begin{tabular}{|c|c|c|c|c|c|}
\hline Item & Variable & Mean & Standard Deviation & Sorting According to Mean & Level According to Mean \\
\hline $12-15$ & Singularity & 3.42 & 0.94 & High & 2 \\
\hline $16-19$ & Inatiation & 3.51 & 0.78 & 1 & High \\
\hline $20-23$ & Taking risk & 3.30 & 0.94 & 3 & Medium \\
\hline $12-23$ & Total mean & 3.41 & 0.79 & - & Medium \\
\hline
\end{tabular}

The statistical data in Table 5 indicate that the respondents' perceptions of the dimensions of the entrepreneurship achievement variable were medium with an arithmetic mean (3.41), and after the initiation ranked first with an arithmetic mean (3.51), followed by singularity with an arithmetic mean of (3.42), and in the third and last place taking risk with a mean $=(3.30)$.

Answering to the main question: 
What is the impact of strategic intelligence on achieving entrepreneurship in Jordanian industrial companies that won the King Abdullah II Award for Excellence? In order to answer this question, the Pearson correlation coefficient was used to determine the correlation relationships between the independent and dependent variables. The results were as follows:

TABLE 6. Correlation coefficients between strategic intelligence and each of its dimensions and achieving entrepreneurship with each of its dimensions

\begin{tabular}{lllll}
\hline \hline Independent/Dependent Variables & Foresight & Organized Thinking & Strategic Vision & Independent/Dependent Variables \\
\hline Singularity & 0.540 & 0.646 & 0.545 & Singularity \\
Initiation & 0.605 & 0.600 & 0.604 & Initiation \\
Taking risk & 0.873 & 0.845 & 0.690 & Taking risk \\
\hline \hline
\end{tabular}

Statistically significant at the level of significance (0.01)

The statistical results in Table 6 show the degrees of the correlation between strategic intelligence and achieving entrepreneurship in a single dimension in a societal and aggregate manner, where the values of correlational coefficients were significant and positive, this indicates the extent of strong direct correlation between the independent total variable and the dependent total variable, where the correlative force reached (0.753). The strength of the correlation relationship at the level of the single dimension of organized thinking was $(0.845)$, which is the strongest correlational relationship between this independent dimension and the overall variable dependent on achieving entrepreneurship. $t$, values of correlational factors for the rest of the independent dimensions were also high in their relationship with the dependent dimension, where the strength of the correlation relationship to the strategic vision dimension reached (0.873), it was (0.845) for the organized thinking, and finally the foresight dimension amounted (0.690). As for the values of correlation coefficients between the independent variable (foresight) and the dependent dimensions, the results indicated that there are a proportional correlations between these variables. $t$ he strongest correlation relationships were with the dependent dimension "taking risk", where the correlation relationship strength reached (0.690), while the weakest correlation was in the dependent variable "singularity" where the strength of this correlation was (0.445).

As for the values of correlation coefficients between the independent variable (organized thinking) and the dependent dimensions, the results indicated that there are a proportional correlations between these variables. $t$, he strongest correlation relationships were with the dependent dimension "singularity", where the strength of the correlative relationship was (0.604), while the weakest of these relationships were the relationship that linked the independent variable the organized thinking with the dependent variable "initiation", where the strength of this relationship was $(0.540)$.

As for the values of correlation coefficients between the independent variable (strategic vision) and the dependent dimensions, the results indicated that there are a proportional correlations between these variables. $t$, he strongest correlation relationships with the dependent dimension were with the "initiation", where the strength of the correlation relationship reached (0.605), while the weakest of these relationships were the relationship that linked the independent variable, the "strategic vision" in the dependent variable "singularity", where the strength of this relationship was (0.448).

\section{Study Hypotheses Test}

Before starting to apply regression analysis to test the hypotheses of the study, some tests were done, in order to ensure the compatibility of the data with the regression analysis assumptions, as follows: It was confirmed that there was no high correlation between the independent variables (Multicollinearity) using Variance Inflation Factor (VIF) test and Tolerance test for each of the study variables.

Taking into account that the value of the VIF does not exceed the value (10) and the value of the Tolerance test is greater than (0.05), and it was also ensured that the data is within the normal distribution by calculating the Skewness coefficient, taking into account that the data follow the normal distribution, if the value of the Skewness coefficient is less than (1). Table 7 shows the results of these tests.

TABLE 7. VIF, tolerance and skewness coefficient test

\begin{tabular}{llll}
\hline \hline Sub Dimensions & Skewness & Tolerance & VIF \\
\hline Foresight & 0.286 & 0.630 & 1.640 \\
Organized thinking & 0.205 & 0.583 & 2.625 \\
Strategic vision & 0.284 & 0.468 & 2.192 \\
\hline \hline
\end{tabular}


The results that the values of the VIF test for all independent variables is less than (10) it ranges between (1.640-2.625) and that the values of Tolerance ranged between (0.468-0.630), which is an indication of the absence of high correlation among the independent variables (Multicollinearity). It was confirmed that the data follow the normal distribution by calculating the Skewness coefficient, as the values were less than (1). The validity of the model will be checked to test the hypotheses of the study.

\section{Main Hypothesis Test Results}

There is no statistically significant impact at the level of significance $(\alpha \leq 0.05)$ of strategic intelligence in its dimensions (foresight, organized thinking, and strategic vision) in achieving entrepreneurship in its dimensions (singularity, initiation, and taking risk) in Jordanian industrial companies that won the King Abdullah II Award for Excellence.

TABLE 8. Results of the analysis of variance to ensure the validity of the model to test the main study hypothesis

\begin{tabular}{llllll}
\hline \hline Source & Coefficient of $R^{2}$ & Sum of Squares & Degrees of Freedom & Average Squares & The Least Calculated Value of $\boldsymbol{f}$ \\
\hline Regression & & 75.450 & 1 & 75.450 & \\
Error & 0.606 & 49.029 & 198 & 0.248 & 302.610 \\
Total & Coefficient of $R^{2}$ & 124.478 & 199 & Average squares & \\
\hline \hline
\end{tabular}

* Statistically significant at the level of significance $(0.05 \geq \alpha)$.

The statistical results in the table show the validity of the model to test the hypothesis of the main study and that there is a statistically significant impact of the dimensions of strategic intelligence (foresight, organized thinking, and strategic vision) in achieving entrepreneurship in its dimensions (singularity, initiation, and taking risk) depending on the calculated value of (302.610) at the level of significance (0.000), which is significant at the level of significance (0.05). $t$ the statistical results in the same table show that the dimensions of strategic intelligence as an indepen- dent variable explains $60.6 \%$ of the variance in the dependent variable (achieving entrepreneurship).

From the above, it is necessary to reject the first main hypothesis with its nihilistic formulation and accept the alternative hypothesis that states: There is a statistically significant impact of the dimensions of strategic intelligence (foresight, organized thinking, and strategic vision) in achieving entrepreneurship in its dimensions (singularity, initiation, and taking risk).

TABLE 9. The results of the progressive multi-regression analysis to predict entrepreneurship achievement through the dimensions of strategic intelligence as independent variables

\begin{tabular}{llll}
\hline \hline The order in which the Independent Variables enter the Prediction Equation & Computed $\boldsymbol{t}$ value & $R^{2}$ Value & Significant Level of $\boldsymbol{t}$ \\
\hline Foresight & 0.530 & 2.065 & 0.040 \\
Critical Thinking & 0.000 & $5.228^{*}$ & 0.640 \\
Strategic vision & 0.655 & 3.190 & 0.000 \\
\hline \hline
\end{tabular}

When performing the Stepwise Multiple Regression Analysis to determine the importance of each independent variable separately in contributing to the mathematical model that represents the dimensions of strategic intelligence in achieving entrepreneurship, Table 9 shows the order of entry of the independent variables into the regression equation. Foresight ranked first and explained $53 \%$ of the variance in the dependent variable (achieving entrepreneurship) followed by the Organized thinking variable, which explains the foresight variable in the amount of $64 \%$. Finally, the Strategic vision variable that explains with the previous variables the amounts of $65.5 \%$ of the variance in the dependent variable (Entrepreneurship achievement).

\section{The First Sub-Hypothesis}

There is no statistically significant impact at the level of significance $(\alpha \leq 0.05)$ to anticipate the achievement of entrepreneurship in its dimensions (singularity, initiation, and taking risk) in Jordanian industrial companies that won the King Abdullah II Award for Excellence.

The statistical results in Table 10 show the validity of the model to test the hypothesis of the first sub-study, and that there is a statistically significant impact at the level of significance $(0.05 \geq \alpha)$ of foresight in achieving entrepreneurship in its dimensions (singularity, initiation, and taking risk) in Jordanian industrial companies that won the King Abdullah II Award. 
TABLE 10. Results of the analysis of variance to verify the validity of the model for testing the first sub-hypothesis

\begin{tabular}{llllll}
\hline \hline Source & Coefficient of $R^{2}$ & Sum of Squares & Degrees of Freedom & Average Squares & The least calculated value of $\boldsymbol{f}$ \\
\hline Regression & & 37.387 & 1 & 75.450 & \\
Error & 0.317 & 82.970 & 198 & 0.248 & 302.610 \\
Total & Coefficient of $R^{2}$ & 121.315 & 199 & Average squares & \\
\hline \hline
\end{tabular}

$* *$ Significance level $(0.05 \geq \alpha)$

The distinction is based on the calculated value of $(f)$ of (86.516) at the level of significance $(0,000)$ which is significant at the level of significance (0.05). The statistical results in the same table also show that the dimensions of strate- gic intelligence as an independent variable explain $31.7 \%$ of the variance in the dependent variable ( entrepreneurship achievement).

TABLE 11. Results of multiple regression analysis to test the impact of foresight in achieving entrepreneurship in its various dimensions

\begin{tabular}{llllll}
\hline \hline Dimensions Organized Abilities Building & Significant level of $\boldsymbol{t}$ & $\mathbf{B}$ & Standard Error & Beta & $\boldsymbol{T}$ value \\
\hline Singularity & 0.146 & 0.071 & 0.178 & 2.220 & 0.034 \\
Initiation & 0.139 & 0.080 & 0.438 & 3.611 & 0.000 \\
Taking risk & -0.062 & 0.064 & -0.071 & -0.982 & 0.226 \\
\hline \hline
\end{tabular}

* Significance level $(0.05 \geq \alpha)$

It is clear from the statistical results presented in Table 11 and from the follow-up of beta coefficients and the $t$-test that foresight affects the sub-variables (singularity and initiation) at the level of significance of $5 \%$, and there is no impact on the variable (Taking risk) dependent on the calculated $t$ values of $(-0.982)$, which are not significant at the level of significance $5 \%$ at the level of significance (0.226).

\section{The Second Sub-Hypothesis}

There is no statistically significant impact at the level of significance $(\alpha \leq 0.05)$ of organized thinking in achieving entrepreneurship in its dimensions (singularity, initiation, and taking risk) in Jordanian industrial companies that won the King Abdullah II Award for Excellence.

TABLE 12. The results of the regression analysis of variance to ensure the validity of the model to test the second sub-hypothesis

\begin{tabular}{lllllll}
\hline \hline Source & Coefficient of $R^{2}$ & Sum of Squares & Degrees of Freedom & Average Squares & $\begin{array}{l}\text { The Least Calculated } \\
\text { Value of } \boldsymbol{f}\end{array}$ & $\begin{array}{l}\text { The Level of } \\
\text { Significance }(\boldsymbol{f})\end{array}$ \\
\hline $\begin{array}{l}\text { Regression } \\
\text { Error }\end{array}$ & 0.521 & 61.849 & 1 & 61.849 & \\
Total & 122.109 & 60.259 & 198 & 0.304 & 302.610 & 0.000 \\
\hline \hline
\end{tabular}

* Significance level $(0.05 \geq \alpha)$

The statistical results in Table 12 shows the validity of the model to test the hypothesis of the second sub-study and that there is a statistically significant impact at the significance level $(0.05 \geq \alpha)$ of organized thinking in achieving entrepreneurship in its dimensions (singularity, initiation, and taking risk) in Jordanian industrial companies that have won the King Abdullah Award, depending on the value of $(f)$ calculated at the level of significance (0.000), which is significant at the level of significance (0.05). Statistical results in the same table also show that the organized thinking dimension as an independent variable, explains 52.1\% of variance in the dependent variable.

TABLE 13. Results of the multiple regression analysis to test the impact of organized thinking on achieving entrepreneurship in its various dimensions

\begin{tabular}{llllll}
\hline \hline Dimensions Organized Abilities Building & B & Standard Error & Beta & $\boldsymbol{t}$ Value & Significant Level of $\boldsymbol{t}$ \\
\hline Singularity & 0.210 & 0.069 & 0.276 & 3.618 & 0.001 \\
Initiation & 0.108 & 0.081 & 0.110 & 1.316 & 0.162 \\
Taking risk & 0.144 & 0.064 & 0.163 & 2.509 & 0.022 \\
\hline \hline
\end{tabular}

* Significance level $(0.05 \geq \alpha)$ 
It is clear from the statistical results mentioned in Table 13 and from the follow-up of beta coefficients and t-test that organized thinking affects the sub-variables (singularity, initiation, and taking risk) depending on the value of $(t)$ calculated in the previous table at the level of significance of $5 \%$ with no impact on the initiation variable depending on the calculated $t$ values of 1.316 at the significance level of 0.162 which is not significant at the level of significance of $5 \%$.

\section{The Third Sub-Hypothesis}

There is no statistically significant impact at the level of significance $(\alpha \leq 0.05)$ of the strategic vision in achieving entrepreneurship in its dimensions (singularity, initiation, and taking risk) in Jordanian industrial companies that won the King Abdullah II Award for Excellence.

TABLE 14. Results of the analysis of variance to ensure the validity of the model for testing the third sub-hypothesis

\begin{tabular}{lllllll}
\hline \hline Source & Coefficient of $R^{2}$ & Sum of Squares & Degrees of Freedom & Average squares & $\begin{array}{l}\text { The Calculated } \\
\text { Value of } \boldsymbol{f}\end{array}$ & $\begin{array}{l}\text { The level of } \\
\text { Significance }(\boldsymbol{f} \text { ) }\end{array}$ \\
\hline Regression & & & & 4 & 67.234 & \\
Error & 0.536 & 65.200 & 193 & 0.289 & 232.551 & 0.000 \\
Total & & 56.120 & 194 & & & \\
\hline \hline
\end{tabular}

* Significance level $(0.05 \geq \alpha)$

The statistical results in Table 14 show the validity of the model to test the hypothesis of the third sub-study and that there is a statistically significant impact at the level of significance $(0.05 \geq \alpha)$ of the strategic vision in achieving entrepreneurship in its dimensions (singularity, initiation, and taking risk) in the Jordanian industrial companies that won the King Abdullah The second Award, depending on the calculated value of $(f)$ at the significance level $(0.000)$, which is significant at the significance level $(0.05)$. The statistical results in the same table also show that the strategic vision dimension as an independent variable, explains an amount of $53.6 \%$ of the variance in the dependent variable.

TABLE 15. Results of the multiple regression analysis to test the impact of the strategic vision on achieving leadership in its various dimensions

\begin{tabular}{llllll}
\hline \hline Dimensions Organized Abilities Building & B & Standard Error & Beta & $\boldsymbol{t}$ Value & Significant Level of $\boldsymbol{t}$ \\
\hline Singularity & 0.361 & 0.071 & 0.370 & 3.762 & 0.000 \\
Initiation & 0.534 & 0.088 & 0.481 & 5.403 & 0.000 \\
Taking risk & -0.082 & 0.063 & -0.096 & -1.546 & 0.128 \\
\hline \hline
\end{tabular}

* Significance level $(0.05 \geq \alpha)$

It is clear from the statistical results mentioned in Table 15 and from the follow-up of beta coefficients and $t$-test that the strategic vision affects the sub-variables (singularity and initiation) depending on the value of $t$ calculated in the previous table at the level of significance of $5 \%$ with no impact on the variable (taking risk) depending on the calculated $t$-values of -1.546 at the level of significance of 0.128 which is not significant at the level of significance of $5 \%$.

\section{Discussion}

1- The results showed that the dimensions of the independent variable (Strategic Intelligence) came average with an arithmetic mean (3.60), the foresight dimension ranked first with an arithmetic mean (3.76), followed by strategic vision with an arithmetic mean (3.59), and finally organized thinking dimension occupied the last rank with a mean of (3.45).The results indicated that the dimensions of the strategic intelligence variable were available in the researched companies, at a medium degree.
2- The results showed that the respondents' perceptions of the dimensions of the variable to achieve entrepreneurship have come average with an arithmetic mean of (3.41), the initiation dimension occupied the first place with an arithmetic mean of (3.51) followed by singularity with an arithmetic mean of (3.42), in the third and last place came taking risk dimension with an arithmetic mean of (3.30). therefore, the perceptions of the study community members about the level of achieving entrepreneurship in the research companies as a whole was moderate.

3- The results indicated that the degrees of the correlative relationship between strategic intelligence and achieving entrepreneurship in a singular dimension and in a comprehensive societal manner, where the values of correlational coefficients were significant and positive. This indicates the extent of the strong proportional relationship between the independent total variable and the dependent total variable where the correlative force reached (0.753). 
4- The results showed the values of correlation coefficients between the independent variable (foresight) and the dependent dimensions. The results indicated that there were proportional correlations between these variables. The strongest correlation was with the dependent dimension "initiation," while the "taking risk" dimension was the lowest.

5- The results indicated a correlation between the independent variable (organized thinking) and the dependent dimensions. The results indicated that there are proportional correlation relationships between these variables. The strongest correlation relationship was with the dependent dimension "singularity", while the weakest of these relationships was the relationship that linked the independent variable the "Organized thinking" with the dependent variable "Taking risk".

6- The results indicated that the values of the correlation coefficients between the independent variable (strategic vision) and the dependent dimensions have a strong proportional correlations. The strongest was with the dependent dimension "initiation", while the weakest of these relationships was the relationship that linked the independent variable to the "strategic vision" with the dependent variable "taking risk".

7- The results indicated that all these relationships between the variables combined, and between them as individual dimensions, are positive and proportional. This confirms that the availability of strategic intelligence increases the achievement of entrepreneurship in the researched companies and strengthens them.

\section{Conclusion and Implications}

Given these results, the current study provides the following recommendations:

1. The researched companies should know the most important benefits provided by strategic intelligence and the most important areas in which these benefits can be employed in a manner that serves the interests of these companies and achieves their goals.

2. Companies need to attract distinguished human resources that are considered scarce resources that are difficult to replace or imitate, and work to technically qualify them, motivate them, and let them gain strategic intelligence dimensions. Further, companies should make those dimensions a basic culture that translates actions and practices that support the competitive position of the company and make it an entrepreneurial company.

3. Companies should develop an information system managed according to the concepts of strategic intelligence that envisions the future based on integrated information and according to a holistic vision in a way that enhances the internal capabilities and supports the competitive position of the company and makes it agile and flexible companies in its target markets.

4. Companies should focus on initiation and taking risks in seizing opportunities in the markets and expanding them, as well as concluding deals between companies and alliances to help provide distinct services from other companies.

5. Companies should support entrepreneurial initiatives by the managers by providing a work environment that utilizes energies and generates ideas that contribute to the establishment of entrepreneurial projects that lead companies to grow and continue.

6. Companies should make managers in the researched companies aware of the importance of creativity in creating an entrepreneurial personality that contributes to work, and develope their behavioral skills to suit the work environment, which provides a work environment that produces artistic creativity that expresses excellence and creativity.

\section{REFERENCES}

Abdel, N. (2017). Strategic intelligence of senior management and its reflection in enhancing group cohesion. Applied Science Journal, 4(25), 45-60.

Akbari, A., \& Safarnia, H. (2012). The relationship of emotional intelligence, market orientation and competitive strategy. Interdisciplinary Journal of Contemporary Research in Business, 4(8), 497-511.

Al-Dulaimi, B. T. (2018). The impact of transformational leadership practices on achieving entrepreneurship: A field study in private colleges in Iraq (Unpublished master's thesis). Al-Sharq Al-Bayt University, Mafraq, Jorden.

Al-Qadi, H. S. (2019). The impact of strategic intelligence on organizational innovation: Knowledge management as an intermediate variable: An applied study on executives in commercial banks operating in the Hashemite Kingdom of Jordan (Unpublished master's thesis). Mu'tah University, Mu'tah, Jorden.

Al-Qasim, M. (2013). The impact of entrepreneurial characteristics on adopting strategic directions for principals in private schools in Amman (Unpublished master's thesis). Middle East University, Amman, Jorden. 
Al-Sakarneh, B. (2008). Entrepreneurship strategies and their role in achieving competitive advantage: An empirical study on telecommunications companies in Jordan. Baghdad College of Economic Sciences Journal, 17(6), 45-50.

Al-Sakarneh, B. (2010). entrepreneurship and organization management. Jordan, Amman: Al Masirah Publishing House.

Asrizam, E. ., Suhaimi, A. R., Dahlia, Z., Awis, Q. S., Nik, R. I. T., \& Yushaida, Y. K. (2018). Determinants of organizational practices and research culture for the enhancement of research performance in Malaysian universities. Journal Of Advanced Research In Social Sciences And Humanities, 3(6), 204-214. doi:https://doi.org/10.26500/jarssh-03-2018-0601

Bakr, S. (2018). The impact of strategic intelligence on organizational creativity, an applied study on the university of Najran. Journal of Economic and Administrative Sciences, 9(19), 34-45.

Egbuniwe, J. O. (2019). The impact of management information systems on the quality of management decisions. International Journal of Business and Economic Affairs, 4(2), 47-57. doi:https://doi.org/10.24088/ijbea-2019-42001

Fuld, M., L. (2016). The new competitor intelligence. California, CA: John Wiley and Sons.

Gadu, M., \& El-Khameesy, N. (2014). A knowledge management framework using business intelligence solutions. International Journal of Computer Science Issues, 11(5), 102-130.

Goleman, D. (2001). The emotionally intelligent workplace. San Francisco, CA: Sage Publications.

Hawes, T. (2012). Competitive intelligence for small-to-medium size businesses. Hawes Consulting Strategic Analysis, 14(6), 56-70.

Herring, J. P. (1992). The role of intelligence in formulating strategy. Journal of Business Strategy, 13(5), 54-60. doi:https:// doi.org/10.1108/eb039518

Hijazi, A. (2011). Small enterprise management: A technology entrepreneurial perspective. Amman, Jorden: Dar Safa for Publishing and Distribution.

Jandab, A. A. (2017). The impact of information technology on entrepreneurial strategies in yemeni telecom companies (Unpublished master's thesis). Al-Sharq Al-Bayt University, Mafraq, Jorden.

Khaddarat, 0. (2011). Economic entrepreneurship and small projects in Jordan. Iraqi Journal of Economic Sciences, 9(30), 30-40.

Layyinaturrobaniyah, Masyita, D., \& Sekartadjie, G. (2016). Fundamental and technical analyses for stock investment decision making. Journal of Administrative and Business Studies, 2(1), 1-17. doi:https://doi.org/10.20474/jabs-2.1.1

Lemon, 0. A. (2018). Practices of diversity of human resources management and their impact on achieving entrepreneurship in universities: A field study Jordanian public universities (Unpublished master's thesis). Mu'tah University, Mu'tah, Jorden.

McGonagle, J. J., \& Vella, C. M. (1996). A new archetype for competitive intelligence. New York, NY: Greenwood Publishing Group.

Rehman, S. (2017). Impact of career development on organizational commitment. International Journal of Business and Administrative Studies, 3(3), 100-111. doi:https://doi.org/10.20469/ijbas.3.10003-3 